\title{
PHYSIOLOGICAL CHANGES SEEN AFTER SIX WEEKS SEQUENCE TRAINING
}

\author{
Rose P. MACDONALD, BA, MCSP, MCPA
}

\author{
Superintendent Physiotherapist, Sports Injuries Unit, \\ Crystal Palace National Sports Centre, London SE 19
}

\section{ABSTRACT}

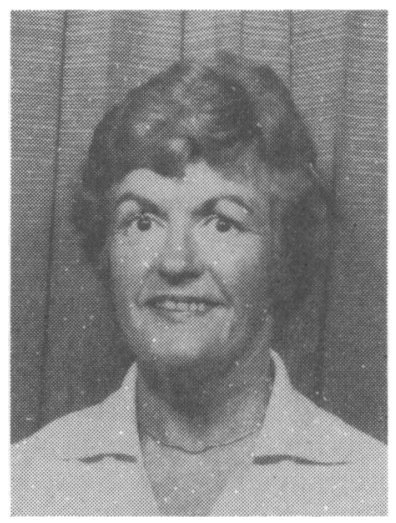

Rose P. Macdonald

Changes in body fat, cardiovascular endurance, muscular endurance, flexibility and strength were assessed in 22 women and 16 men after 6 weeks sequence training. It was found that two training sessions per week were sufficient to cause a significant increase in the majority of measurements made. The extent of the improvement in women was inversely related to the starting value, with most measurements, whereas this was not found in men.

The measurements in this small group were comparable to those found in a large series in Canada, with the exception of the proportion of body fat which was lower in this UK series.

Key Words: Sequence training, Fitness, Endurance.

\section{INTRODUCTION}

In view of the current interest in fitness it was decided to assess whether apparatus currently in use in the Sports Injuries Unit for rehabilitation and fitness maintenance, would also serve to improve fitness in the otherwise healthy individual, as measured by such parameters as predicted $\mathrm{VO}_{2}$ max, muscular endurance, etc. Therefore the opportunity was taken, when the apparatus was not being used therapeutically, to measure the effect it had on the uninjured. It was felt that the simple, relatively mobile design of the equipment could be of widespread value in injury prevention, by training the major muscle groups of the body for general fitness, and specific muscle groups for particular athletic activities. In addition, the measurements made on normal subjects, before and after the training, could provide a norm, albeit small in number, for healthy men and women in the UK for comparison with values published from North America (Yuhasz, 1978).
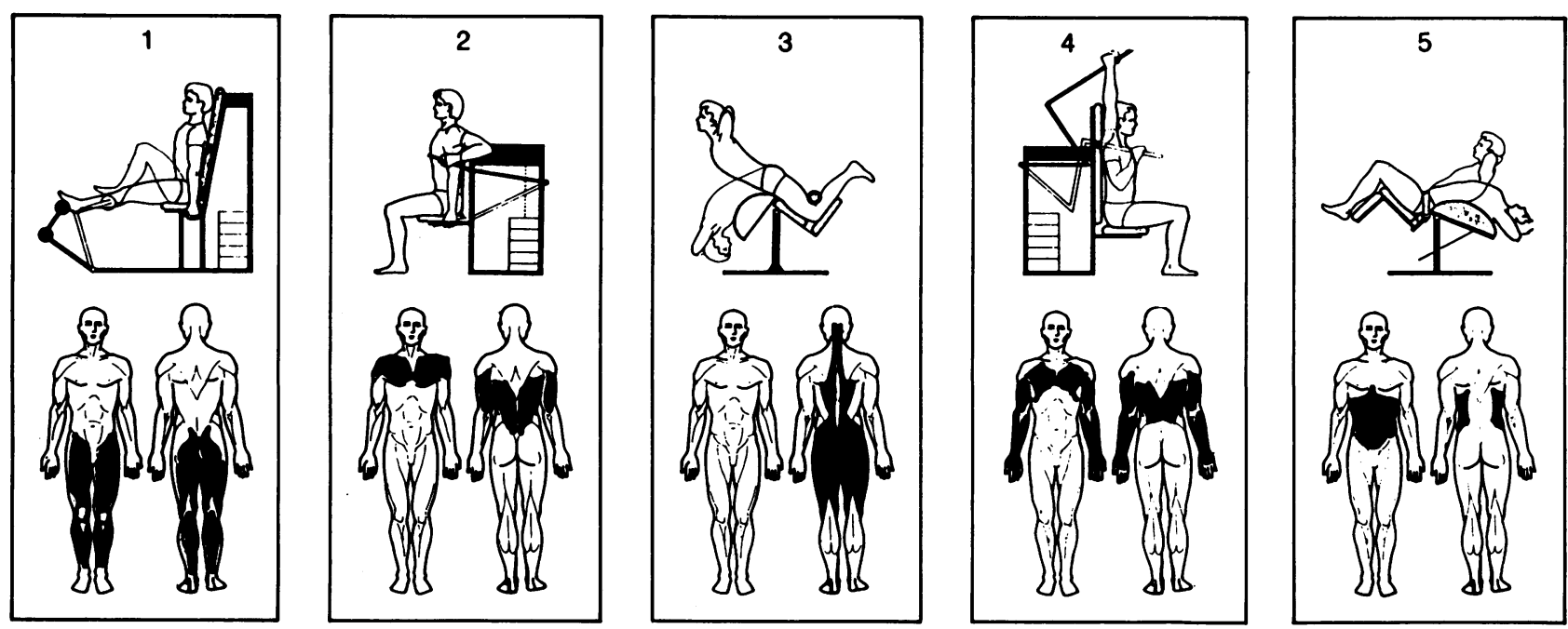

Fig. 1 showing diagrams of the 5 pieces of sequence training equipment used, together with the main muscle groups involved. 
The apparatus used was based on sequence (or circuit) training consisting of five pieces of weight resistance equipment arranged in a circuit (Masolet Sequence Training Exercise Equipment). Five people could work out at the same time, and the load for each subject, as they moved to the next station could easily be adjusted.

\section{Description of Apparatus}

The five pieces which form the system employ the overload principle for strengthening muscles in accordance with the De Lorme method of progressive resistance exercises. Each piece works specific muscle groups through a full range of contraction from a position of "on stretch" with optimal resistance throughout the range. Due to the variation of the ratio between the lever and the weights, the resistance is approximately $100 \%$ on initiation of movement, and $65 \%$ at the end of the range of motion. The exercise stations are arranged in order to allow each muscle group to rest as long as possible between periods of activity. The five pieces (Fig. 1) are:

\section{Leg Press (leg and hip joint muscles)}

In a seated position with the spine and thighs supported and the hands grasping two handles, the legs are extended against resistance to the lock-out position and returned to full flexion. Weight loads progress from $10 \mathrm{~kg}-150 \mathrm{~kg}$.

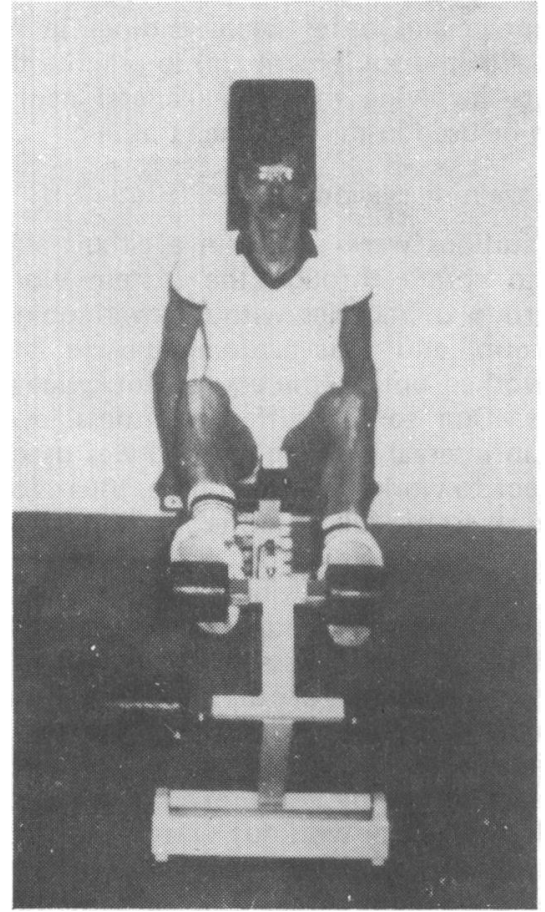

2. Arm Press (arm and chest muscles)

In a seated position with the spine supported and the hands grasping the handles, the arms are extended downwards against resistance and returned to full flexion. Weights may be adjusted from $10 \mathrm{~kg}-150 \mathrm{~kg}$.

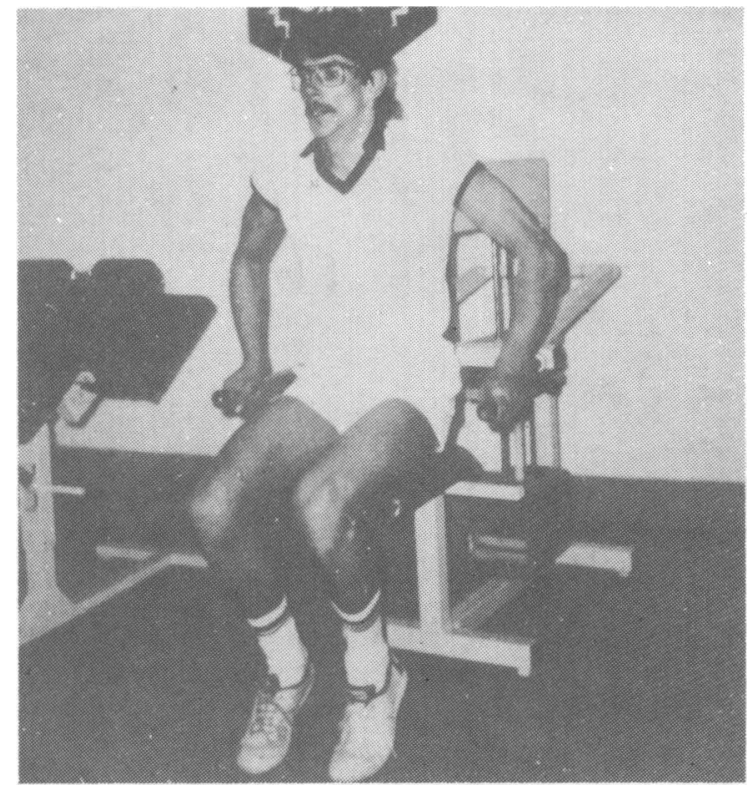

3. Back Extension (back and buttock muscles)

By fixing the legs while in a recumbent semi-kneeling position with the trunk moulded around a curved cushion support, and the hands clasped behind the head, the back is extended to the horizontal position and lowered. There are five adjustable positions to increase the muscle loading.

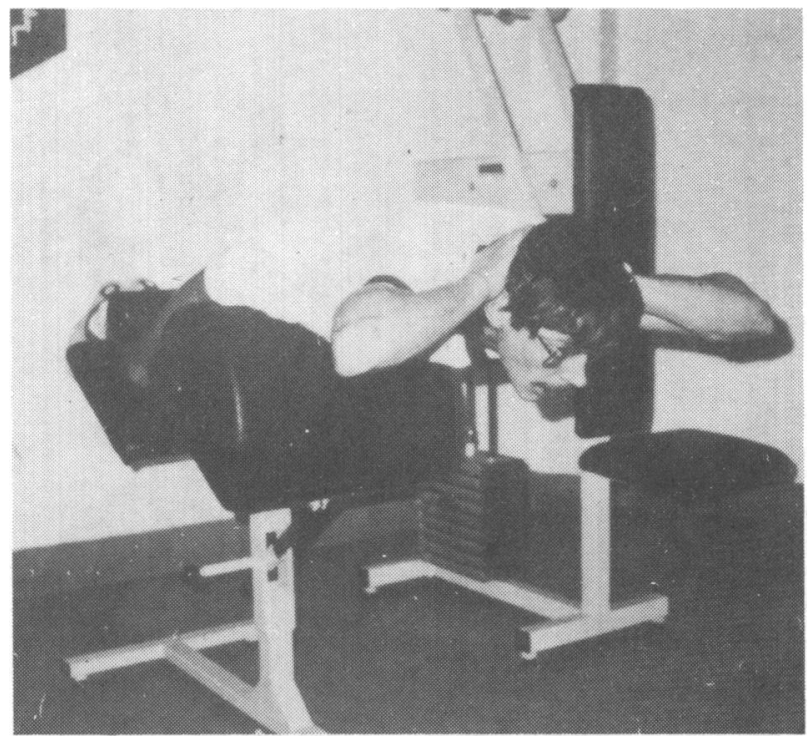


4. Arm Pull (arm and shoulder muscles)

In a seated position with the head and cervical spine supported, and the hands grasping handgrips above the head in a fully stretched position, the handgrip is pulled down against resistance to full flexion. Weights may be adjusted from $10 \mathrm{~kg}-90 \mathrm{~kg}$.

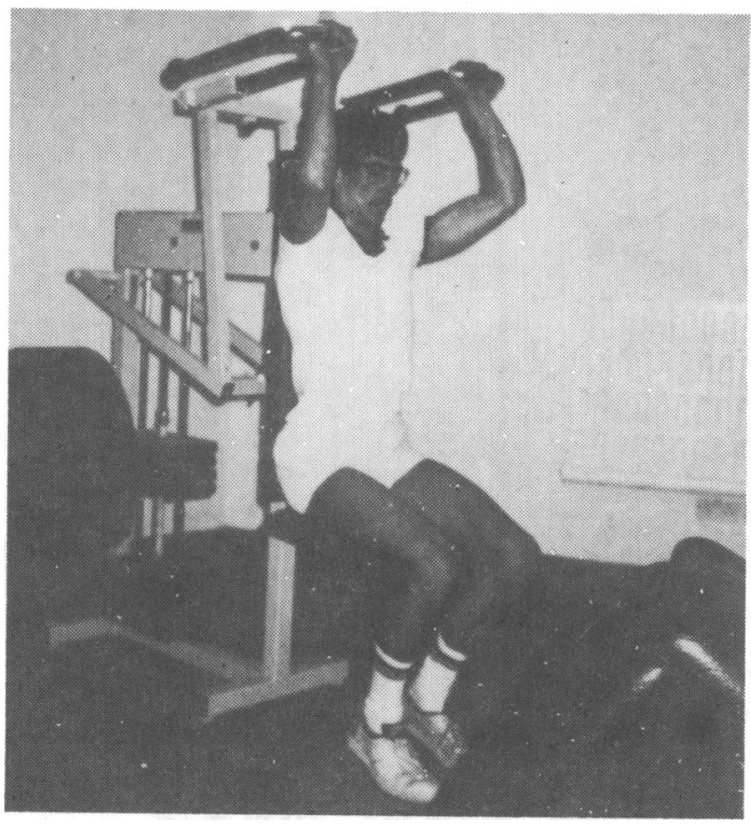

\section{Abdominal Exerciser (abdominal muscles only)}

In the supine position with the knees flexed and the hip joint fixed by a belt, and the back arched over a curved cushion support; the head and thorax are raised upwards. Five adjustments can be made to increase the load intensity.

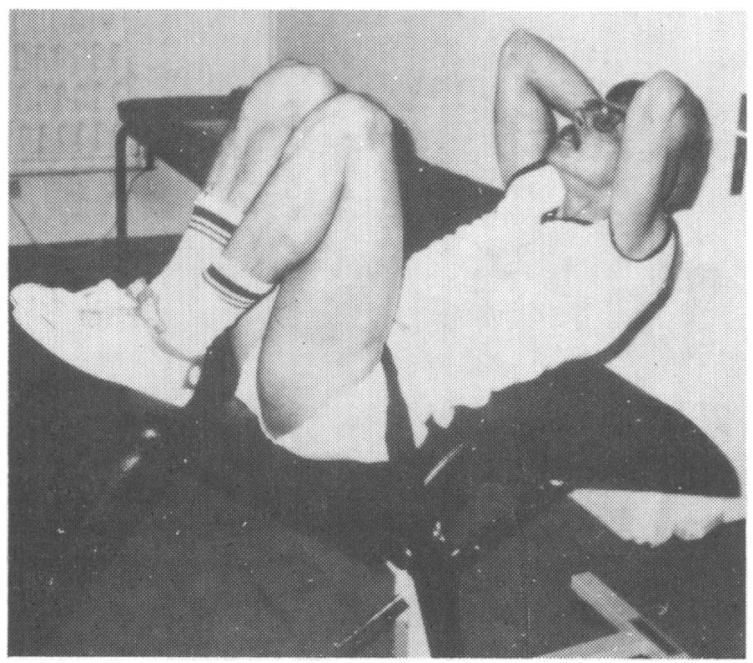

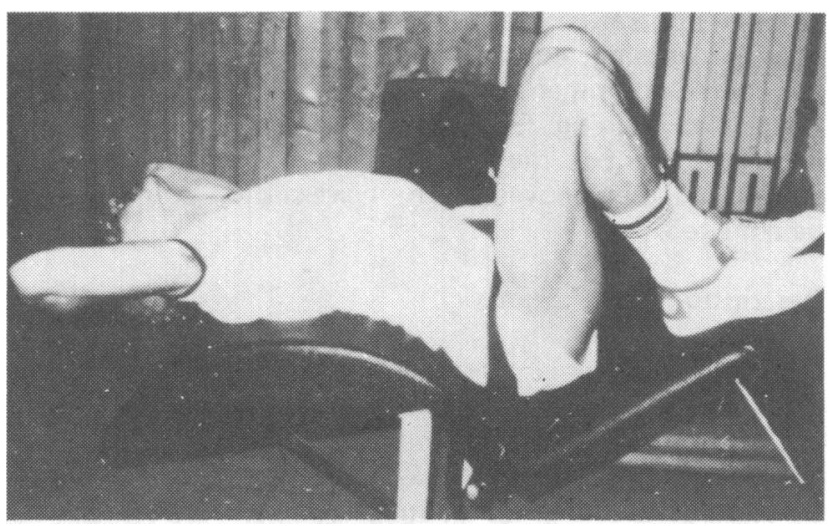

Training Routine

Twenty-two healthy women and 16 healthy men aged 25-50 years took part in a general fitness course lasting six weeks. The routine consisted of a warm up, training session, and warm down.

\section{Warm up}

Before each session the subjects warmed up with flexibility exercises to increase the range of motion at the joints, followed by gradual stretching to increase the extensibility of the muscles and thus help to prevent muscle strains, and lastly, specific activity exercises performed on the equipment using low weights and high intensity to break the "sweat barrier" and allow the proprioceptive and other nerve endings in muscles to get the feel of the equipment and to practise the specific movements involving the same general neuromuscular pattern to be used in the sequence training.

\section{Sequence training session}

The five stations were set up in a circuit allowing the subjects to rotate through the system working each specific group of muscles without overlapping any particular group, and thus avoiding muscle fatigue. The subjects worked out on the equipment twice a week for six weeks. Due to the different fitness levels of the subjects, an interval training method was used to enable each subject to work at his own pace, thus allowing each one to work to his full potential, at his own speed and intensity, without holding up those of greater physical capacity. Maximum repetitions in $\mathbf{2 0}$ seconds followed by 10 seconds rest, to rotate to the next station and adjust the weights as necessary, was found to be a suitable routine. In view of the individual variation in cardiovascular condition, age, and physical fitness of each subject, the aim was to work up to $60-80 \%$ maximum heart rate for the entire exercise period (Åstrand, 1960). The complete workout was monitored by stopwatch. The load for each individual was determined at the initial assessment in accordance with the subject's 
capability. The load built up gradually, together with the number of circuits, until all the subjects were working 12 full circuits (or sets) which took $\mathbf{3 0}$ minutes to complete.

\section{Warm down}

Immediately on termination of the last circuit, the pulse was counted for 15 seconds and the minute value recorded. At the end of the session exercises of gradually diminishing intensity were performed to return the body functions to the pre-exercise level. This was accomplished by doing one circuit on the equipment, using light weights and relaxing during the full stretch on each piece of equipment.

\section{METHODS OF ASSESSMENT}

\section{A. Body fat measurement}

The total amount of body fat was predicted by measuring with a Harpenden calliper the thickness of skinfolds at seven sites on the body (Yuhasz, 1962). This method was chosen because of considerable personal experience in it's use, and because these seven skinfold sites were also used in the North American series with which these findings are compared. The sites measured were: juxta-nipple (men only) triceps (midarm), sub-scapular, supra-iliac, umbilical, mid-front tight, mid-rear thigh (women only) and mid-calf. The body fat and lean body mass (fat free weight) were calculated from these measurements.

\section{B. Cardiovascular endurance}

A sub-maximal exercise test on a bicycle ergometer was carried out to measure $\mathrm{O}_{2}$ uptake on the basis of the heart rate response. The subject rode at either $50 \mathrm{rpm}$ or $60 \mathrm{rpm}$ at their preference. The loading was set to increase the heart rate to at least 120 beats per min. taking into account the age and fitness of the subject. If after $4 \mathrm{~min}$. the heart rate had not reached the required level then the loading was increased in stages of 25 watts. Loads varying between $75 w-125 w$ for women, and between $150 \mathrm{w}-225 \mathrm{w}$ for men were used. When the heart rate, measured by a pulse meter, had stabilised, usually after about $6 \mathrm{~min}$. exercise, this was considered to be the "steady state". Using Åstrand's nomogram the predicted $\mathrm{VO}_{2} \max (\mathrm{ml} / \mathrm{kg} / \mathrm{min})$ was calculated from the steady state heart rate, loading, body weight and age of the subjects. For subjects over 30 years of age the calculated $\mathrm{VO}_{2}$ max was adjusted by using the correction table (Âstrand and Rodahi, 1977).

\section{Muscular endurance}

This assessment was based on the endurance of the major muscle groups using the body as the resistive force. Six exercises were used in which the subject had to repeat the exercise as often as possible in a given time. The subjects were allowed to pace themselves, and 10 seconds were allowed between exercises to record results.

(i) Push-ups (Women 30 seconds: men 60 seconds) In the prone position with the hands placed beside the chest, palms flat on the floor and the toes tucked under, the arms are straightened to raise the body keeping the back straight, until only the palms and toes are in contact with the floor. The body is lowered until the chest or chin touches the floor to complete the movement. Women who could not perform this movement were allowed to keep the palms and knees in contact with the floor while executing the movement. (Principal muscles used: Pectorals and Triceps. Equipment piece no. 2).

\section{(ii) Sit-ups (Women 30 seconds: men 60 seconds)}

Lying in the supine position with the knees flexed at $90^{\circ}$ the feet held firmly on the floor and the hands clasped behind the head; the upper body is raised to touch both elbows to both knees and return to the floor. (Principal muscles involved: Rectus abdominis, Ilio-psoas. Equipment piece no. 5).

\section{(iii) Chest raise (Women and men 30 seconds)}

In the prone position with the legs straight and held down, and the hands clasped behind the head, the upper body is raised as high as possible from the floor and lowered. (Principal muscles involved: neck and shoulder, Erector spinae, Sacrospinalis, Glutei and Hamstrings. Equipment piece no. 3).

(iv) Double backward leg-raise (Women and men 30 seconds)

In the prone position with the arms by the sides, palms facing down, and the chest firmly held down, both legs are lifted upward to clear the thighs from the floor. (Principal muscles involved: Erector spinae, Sacrospinalis and Gluteus maximus. Equipment piece no. 3).

(v) Side leg-raise (Women and men 60 seconds)

In the side lean rest position with the body supported on a straight arm and side of the foot, with the upper hand on the hip or raised in the air for balance, the upper leg is raised to the horizontal and lowered. After $\mathbf{3 0}$ seconds the position is reversed and the exercise is repeated with the other leg. The count is cumulative. (Principal muscles involved: Deltoids, Pectorals, Trapezius and Latissimus Dorsi for balance, Sartorius, Glutei, Vastus lateralis and Tensor fasiae latae for the leg raise. Equipment pieces nos. 2 and 4 (stabilisers)).

(vi) Sitting tucks (Women 30 seconds: men 60 seconds) 
In the long sitting rest position with the hands placed beside the hips with palms down, the heels are raised about $15 \mathrm{~cm}$ ( 6 inches) off the floor, the knees are brought to the chest and then the legs are fully extended keeping the heels off the floor. (Principal muscles involved: Psoas, lliacus for flexing, the Quadriceps and Rectus femoris for leg extension. Equipment piece no. 1).

\section{Flexibility}

(i) Sit and reach

In the long sitting position with the feet about $10 \mathrm{~cm}$ (4 inches) apart and placed against a vertical support, the subject reaches forward as far as possible with both hands and holds the position for three seconds. The knees are kept straight throughout the movement. The distance of the fingertips from the support is measured. (Equipment piece no. 3).

\section{(ii) Back extension}

While lying in the prone position with the hands clasped behind the head, and with the legs and hips held in firm contact with the floor, the subject raises the chest as high as possible. The distance from chin to floor is measured vertically. (Equipment piece no. 3).

\section{E. Strength}

Right and left hand grip.

Using a hand dynamometer which was fixed to a bench and with the arm held horizontally with the elbow extended, the maximum squeeze of two trials was recorded for each hand.

\section{STATISTICS}

The mean and standard deviation was calculated for each set of data for each sex. The value for each individual, for each test, after the six weeks Sequence Training was subtracted from the value before training started, and the mean and standard deviation of these values were determined. Student's ' $t$ ' test was applied to these latter differences and significance only considered when the probability was $P<0.025$.

\section{RESULTS (Table I)}

\section{A. Body weight and body fat (Fig. 2)}

There was a significant fall in the mean body weight in the women $(1.4 \mathrm{~kg})$ but not in the men, and both groups lost body fat. The markedly greater loss of body fat than body weight in the men would suggest that the body fat had been replaced by lean body mass keeping the total body weight constant. The similar drop in body fat and body weight in women implies no increase in muscle mass.

\section{B. Cardiovascular endurance (Fig. 3)}

This was assessed from a steady heart rate at a constant load on a bicycle ergometer and an approximate estimation of $\mathrm{VO}_{2}$ using Åstrand's index. The steady state heart rate decreased slightly, but not significantly, in both sexes (less than $10 \%$ ). The predicted $\mathrm{VO}_{2} \max$ increased significantly.

\section{TABLE I}

The mean and standard deviation of various measurements in men and women before and after 6 weeks sequence training. ( $n=$ number of subjects in test.

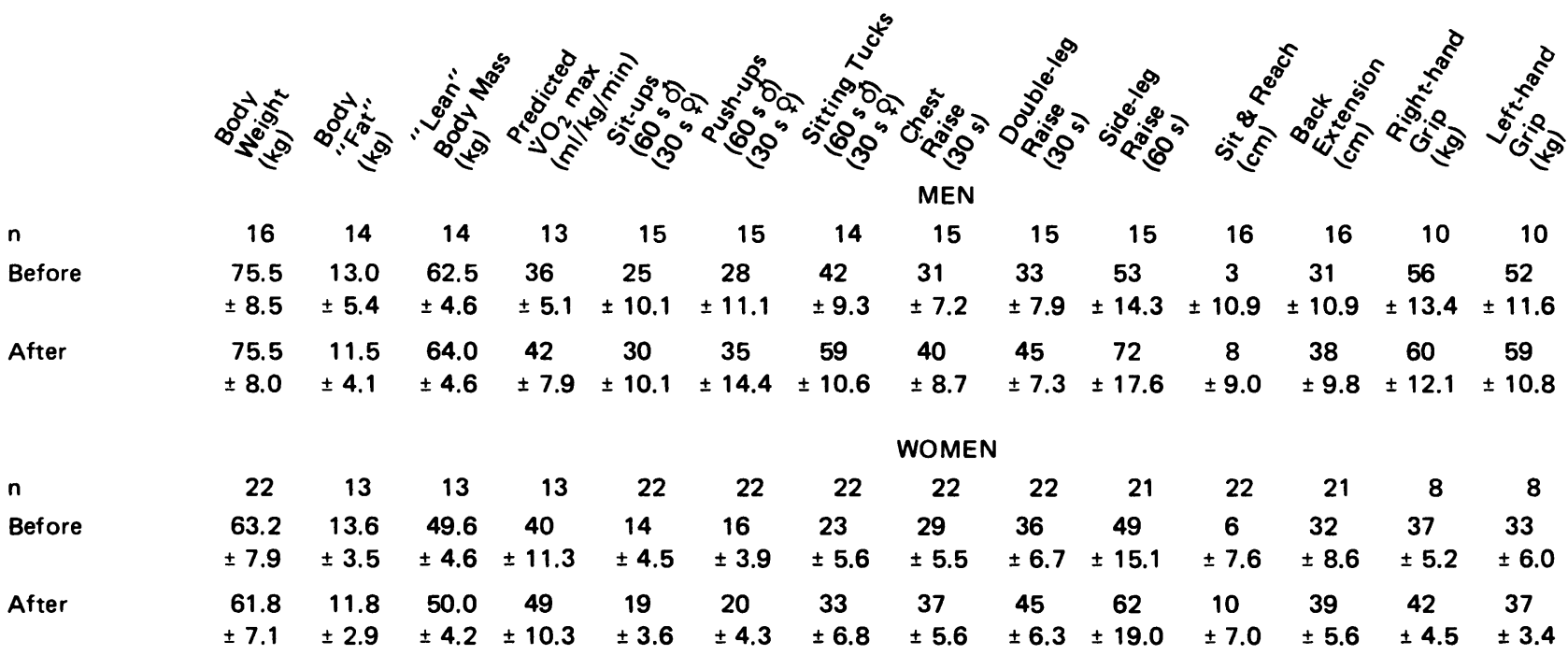



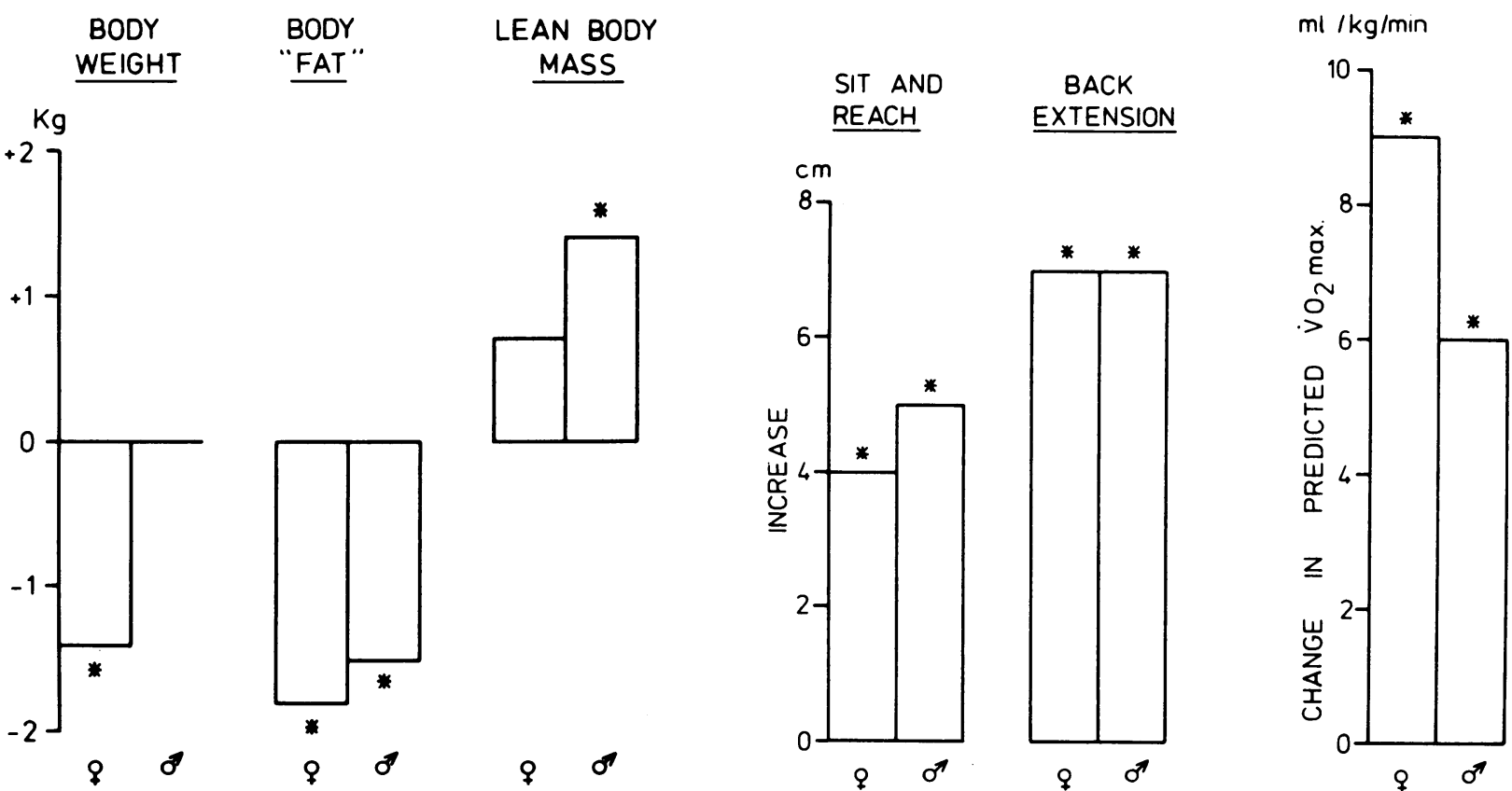

Fig. 2: The mean change in body weight, body "fat" and lean body mass in men and women after 6 weeks sequence training.

${ }^{*}=P<0.025$.

Fig. 3: The mean increase in sit and reach, back extension and predicted $\mathrm{VO}_{2}$ max in men and women after 6 weeks sequence training.

${ }^{*}=P<0.025$.

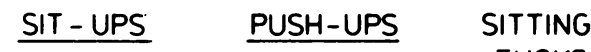
TUCKS

CHEST RAISE

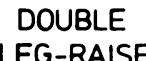

LEG-RAISE
SIDE

LEG-RAISE
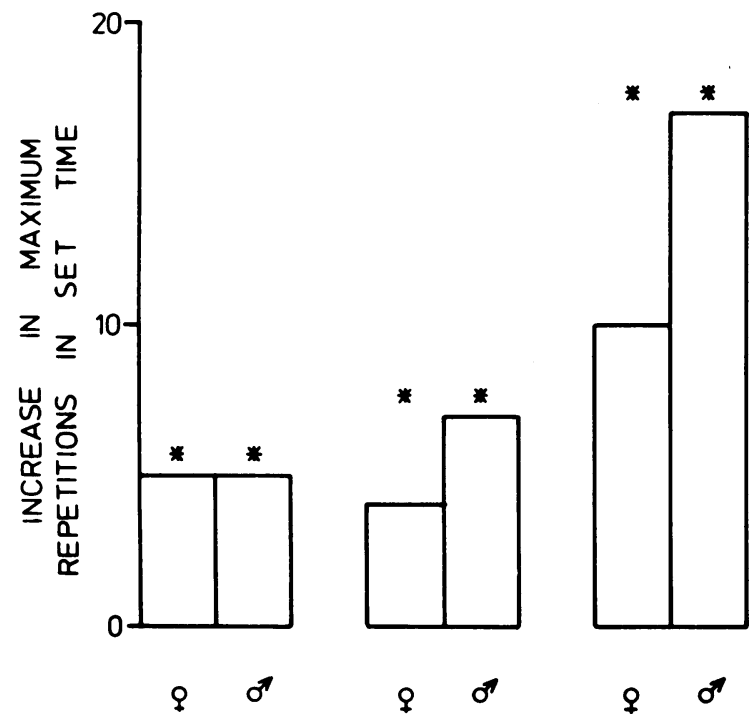

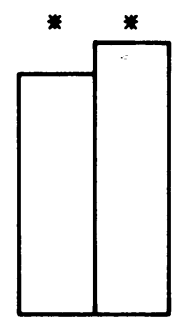

q

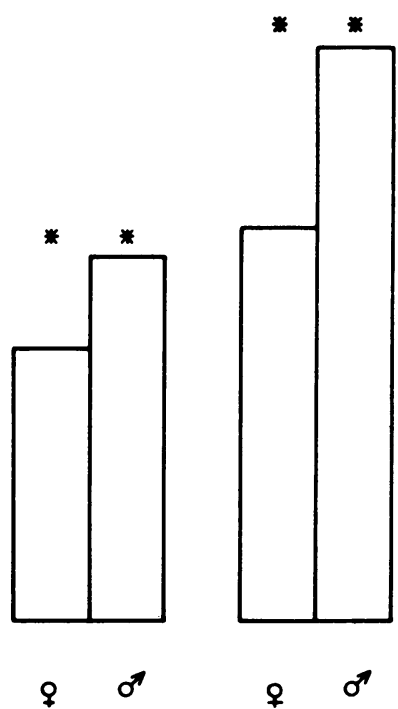

Fig. 4: The mean increase in various performance tests in men and women after 6 weeks sequence training. ${ }^{*}=P<0.025$. 


\section{Muscular endurance (Fig. 4)}

The muscular endurance tests, namely, push-up, situp, chest raise, double leg-raise, side leg-raise and sitting tucks, all showed a highly significant increase in performance in both sexes. The increase varied between an increase of $40 \%-45 \%$ for both sexes in the tucks, to approximately $25 \%$ for the push-ups.

\section{Flexibility (Fig. 3)}

The sit and reach, and the back extension showed significant increases. The sit and reach distance increased by $66 \%$ in the women and $166 \%$ in the men. The back extension increased by about $20 \%$ after the six weeks sequence training.

\section{E. Strength}

The right and left hand grip as a measurement of strength increased significantly by about $10 \%$ probably because the hand flexors were worked when using every piece of equipment.

\section{DISCUSSION}

The results from these studies in healthy subjects doing sequence training show that this form of training improves fitness as assessed by the parameters measured. This is no surprise except in the concept that relatively infrequent training (twice a week) can improve fitness in a general sense. These studies do not provide any evidence that had the training sessions been more frequent and for a longer time, the improvement would have been greater. Certainly it seems that the interval between one sequence training session and another in this series is not long enough to prevent accumulation of improvement. It is interesting to speculate whether the intensity of the training affects the interval between sessions, such that the more intense the training the greater the time interval before all improvement is lost.

An attempt was made to answer the question whether the less well trained subjects improved the greatest during the six weeks sequence training period. This was assessed statistically by plotting the before training value against the change after six weeks training and fitting a line by the method of least squares and determining whether the slope of the line was significantly different from zero $(p=<0.025)$. The results showed that there was a proportionally greater improvement in those whose muscular condition was less fit to start with in the following measurements in women: pushups, sit-ups, chest-raise, double leg raise and back extension. Thus it seems that in these muscle groups the more untrained at the start the greater the improvement. There was a positive correlation with body weight loss and with fat weight loss as a result of sequence training.

In men, the lower the predicted $\mathrm{VO}_{2} \max$ at the start, the greater the improvement. Like the women, a high body fat was accompanied by a greater fat loss due to the training. With the side-leg raise, sitting tucks and sit and reach tests, the improvement was not correlated to the condition at the start in either men or women.

It was surprising to find that the sit and reach measurements improved considerably despite there being no aspect of the equipment designed to alter this parameter. It may be that this increase was due to the gradual stretching exercises during the warm up period.

The predicted $\mathrm{VO}_{2} \max$ rose approximately $20 \%$ in both men and women. This was impressive considering that there were only five stations in the sequence and the workout was only twice a week. This confirms earlier work by Fox (1979) that in interval training the frequency and duration of training is not a major factor affecting $\mathrm{VO}_{2}$ max, whereas intensity is of major importance.

The findings in this study also confirmed previous work that in women the lean body mass does not increase significantly with weight training whereas it

\section{TABLE II}

A comparison, between UK and Canadian subjects, of the means of various measurements used in this study.

$\begin{array}{ccccccccrr}\begin{array}{c}\text { Push-ups } \\ (30 \mathrm{~s})\end{array} & \begin{array}{c}\text { Sit-ups } \\ (30 \mathrm{~s})\end{array} & \begin{array}{c}\text { Chest } \\ \text { raise } \\ (30 \mathrm{~s})\end{array} & \begin{array}{c}\text { Double } \\ \text { leg raise } \\ (30 \mathrm{~s})\end{array} & \begin{array}{c}\text { Side } \\ \text { leg raise } \\ (60 \mathrm{~s})\end{array} & \begin{array}{c}\text { Sitting } \\ \text { tucks } \\ (30 \mathrm{~s})\end{array} & \begin{array}{c}\text { Sit } \\ \text { and reach } \\ \mathrm{cm}\end{array} & \begin{array}{c}\text { Back } \\ \text { extension } \\ \mathrm{cm}\end{array} & \begin{array}{c}\text { Grip } \\ (\mathrm{kg})\end{array} & \begin{array}{c}\text { Fat } \\ (\%)\end{array} \\ 16 & 14 & 29 & 36 & 49 & 23 & 6 & 32 & 37 / 33 & 21.5 \\ 12 & 13 & 31 & 34 & 54 & 37 & 8 & 40 & 32 / 29 & 27.7\end{array}$

Men:

$\begin{array}{lcccccc} & (60 \mathrm{~s}) & (60 \mathrm{~s}) & & & & (30 \mathrm{~s}) \\ \text { UK } & 28 & 25 & 31 & 33 & 53 & 42 \\ \text { Canada } & 28 & 26 & 32 & 28 & 68 & 58\end{array}$

\section{3}

6 
does in men (Brown et al, 1974; Wilmore, 1975). The loss in body fat as measured by skinfold thickness was similar in both sexes, so that the increase in lean body mass in men compensated for the loss of "fat" resulting in no alteration in total body weight.

Though the numbers in this series are small it was felt that it might be of interest to compare the various mean findings for the performance tests with those published for average values in a large group in Canada (Yuhasz, 1978). It can be seen in Table II that the pre-training values in the series show the body "fat" to be less in both men and women in the UK. Flexibility as well as side leg raise and sitting tucks seem to be greater in
Canadians than in the small series reported here. Of interest to this particular series is that the measurements made are, overall, comparable to those reported elsewhere.

Thus it seems that a half hour of sequence training twice a week is capable of improving overall fitness as well as resulting in a re-distribution of body composition.

\section{ACKNOWLEDGEMENTS}

I wish to thank Professor I. Macdonald for his help with the statistics and with preparation of the manuscript, and Mr. Peter Hunt, MCSP, of Masolet (UK) Ltd., Bristol, for permission to reproduce Fig. 1.

\section{REFERENCES}

Åstrand, I., 1960 "Aerobic work capacity in men and women with special reference to age". Acta Physiol.Scand. 49 (Suppl. 169): 45-60.

Åstrand, P. O. and Rodahl, K., 1977. Textbook of Work Physiology. 2nd Ed. p. 455-6. McGraw Hill, New York.

Brown, C. H. and Wilmore, J. H., 1974 "The effects of maximal resistance training on the strength and body composition of women athletes". Med. \& Sci. in Sport 6: 174-177.

Fox, E. L., 1979. Sports Physiology. 1st Ed. p. 224. Saunders, Philadelphia.

Wilmore, J. H., 1975 “Inferiority of female athletics: myth or reality". J.Sport Med. 3: 1-6.

Yuhasz, M. S., 1962 "The effects of sports training on body fat in man with predictions of optimal weights". PhD dissertation. University of Illinois.

Yuhasz, M. S., 1978 "Physical fitness appraisal and exercise prescription monograph". Univ. of Western Ontario, Repro. Services. 